\title{
Health behaviour and health beliefs among Finnish middle-aged men
}

Anita Näslindh-Ylispangar, Marja Sihvonen and Pertti Kekki Department of General Practice and Primary Health Care, University of Helsinki, Finland and Seppo Sarna Department of Public Health, University of Helsinki, Finland

\begin{abstract}
Background: This study was part of a major project studying the metabolic syndrome in Finnish men. The final sample composed of 273 (39\%) men who voluntarily completed the Health Behaviour Questionnaire. Aims: To identify key determinants of health behaviour and health beliefs in middle-aged men, and to analyse how they are associated with underlying health covariates. Methods: A stepwise logistic regression model was used to estimate the adjusted odds of the outcome by socio-demographic, health-behaviour, health-belief and clinical factors. Findings: Five models were developed: (1) use of medications, (2) alcohol consumption, (3) self-rated health status, (4) burnout, and (5) motivation to change unhealthy behaviours. Existing illness or injury and occupation had the strongest associations with medication use, in which industrial workers were more likely to use medications than office personnel. A positive association was found between alcohol counselling by family members and less use of alcohol. Lack of illness or injury, good dental health, and normal waist circumference had the strongest associations with perceived good health. Depression and insomnia were the most significant predictors for burnout. Men who exercised 4-7 times a week, or who used alcohol infrequently or not at all, were over two times more likely to be motivated than inactive men. Conclusions: Many relevant predictors that were significantly associated with the selected key determinants of health behaviour and health beliefs of middle-aged men were found in this study. The promotion of regular physical activity and healthy lifestyles among middle-aged men is currently one of the most important priorities of preventive work in primary health care. More gender-specific studies are needed to obtain a deeper understanding regarding men's health issues.
\end{abstract}

Key words: expression of emotions; health behaviour; health beliefs; logistic regression analysis; men's health

Received: March 2007; accepted: November 2007

\section{Introduction}

\section{The gender view}

On average, men have less healthy lifestyles than women. They receive less information from physicians, adopt health-promoting behaviours less often (Verbrugge, 1985; Roter and Hall, 1997;

Address for correspondence: Anita Näslindh-Ylispangar, Kauriintie 3 G 49, 00740 Helsinki, Finland. Email: anita. ylispangar@kolumbus.fi
Sandman et al., 2000), and are less emotionally expressive than women (Courtenay, 2000). Men, in turn, suffer increased fatal chronic illness and less acute illness. Men also have higher cholesterol and blood-pressure readings (Galdas et al., 2005). Furthermore, psychophysiological responses to stress, such as medication use, are common among men, who also recover slowly from stress (Lash et al., 1990; Roter and Hall, 1997; Courtenay, 2000; 2003; Courtenay and Keeling, 2000; Sandman et al., 2000).

(C) 2008 Cambridge University Press 


\section{Health beliefs and health behaviour}

Health beliefs are closely related to adults' immediate social experiences. Adults prefer to define health in terms of their body and vitality, whereas health behaviour is understood as meaning that individuals are responsible for their own health (Marks et al., 1999). Attitudes and beliefs are important determinants of health, affecting both healthy and risky behaviours (Fishbein and Ajzen, 1975; Ajzen, 1985). Unrealistic optimism, for instance, has a negative influence on health perceptions, causing people to rate their health risks as less severe than their peers rate (Weinstein, 1987; Van der Pligt, 1994). Risky health behaviours, such as drinking, are associated with greater perceived susceptibility to related health risks (Vollrath et al., 1993). However, these risks are different in men and women.

Although men's health behaviours are important determinants of excess mortality and premature death (Courtenay, 2000), it was only during the 1990s that men's gender-specific health care needs have begun to attract more serious research attention (Lash et al., 1990; Griffiths, 1996; Roter and Hall, 1997; Moynihan, 1998; Courtenay, 2000; 2003; Courtenay and Keeling, 2000; Sandman et al., 2000; Galdas et al., 2005).

\section{Determinants of men's health and well-being}

In his recent review, Courtenay (2003) identified 30 key determinants of physical and mental health and well-being in men and boys in the United States. He systematically demonstrated that men and boys are more likely than women and girls to engage in behaviours that increase the risk of disease, injury, and death. Courtenay summarises these findings in terms of three main categories: Health behaviours, health-related beliefs, and expression of emotions and physical distress underlying factors that influence the health behaviours and health beliefs of men and boys, and health care.

Earlier studies in Finland have also shown that men have several high-risk health behaviours that can cause serious physical and mental health problems (Helakorpi et al., 2000; NäslindhYlispangar et al., 2005). The purpose of this study was to identify determinants of health and wellbeing in middle-aged men living in Helsinki and to analyse how these key determinants of health behaviour and health beliefs are associated with underlying health covariates.

\section{Methods}

\section{Data collection}

A sample of 690 men (all of the men who were born in 1961 in the northeastern health care region of the Helsinki area) was drawn from the population register filed by the Statistics Finland Bureau.

The final sample composed of 273 (39\%) men who voluntarily completed the Health Behaviour Questionnaire (HBQ; Helakorpi et al., 2000) and attended health examinations with public health nurses. Written consent was obtained from each participant.

\section{Measurements}

The 96-item HBQ, of which 16 single-item variables were used in this study, was originally developed for the measurement of health in a broad sense. It includes questions regarding sociodemographic factors, subjective health status, chronic diseases, and lifestyle. If two variables, for example, education and occupation, were highly correlated, only one was selected. Similarly, if the distributions of the variables were skewed, the variables were excluded from the analysis.

Measurements, such as body mass index (BMI), waist circumference, and self-reported information from the HBQ (Helakorpi et al., 2000) were used to ascertain associations between dependent variables and their underlying factors.

Trained public health nurses determined the BMI and waist circumference at the Helsinki Health District. The clinical measurements were recorded by the same nurses, using the same instruments, and in the same environment, thereby ensuring the reliability of the data.

\section{Dependent and independent variables}

From the HBQ, five variables that served as equivalents to the categories identified by Courtenay (2003) functioned as dependent variables: (1) use of medications (behavioural responses to stress), (2) alcohol consumption (risk-taking behaviour), (3) self-rated health (health beliefs), (4) burnout (expression of emotions) and, (5) motivation 
Table 1 Courtnay's determinants of health and well-being and their equivalents from Health Behaviour Questionnaire in this study

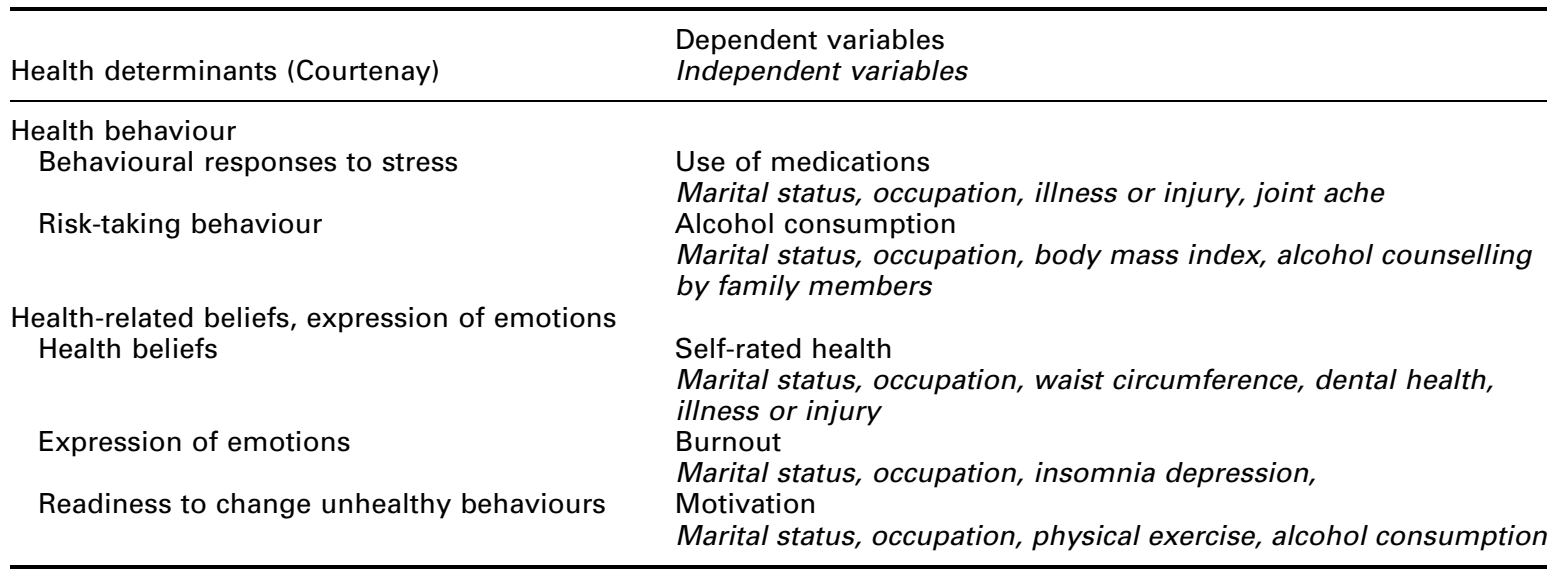

(readiness to change unhealthy behaviours). Twelve independent variables (marital status, occupation, BMI, waist circumference, joint ache, dental health, illness or injury, insomnia, depression, alcohol counselling by family members, physical exercise, and alcohol consumption) were selected from the HBQ on the basis of the literature and correlations between outcome measures and eligible predictors were examined.

BMI and waist circumference were continuous variables. To be considered a risk factor, the following thresholds were required: BMI (overweight or obese $\geqslant 25.0 \mathrm{~kg} / \mathrm{m}^{2}$; normal range, $<25.0 \mathrm{~kg} / \mathrm{m}^{2}$ ) and waist circumference (abdominal obesity $\geqslant 94 \mathrm{~cm}$; normal, $<94 \mathrm{~cm}$ ). The criteria for objective health measurements were based on the literature (Lakka et al., 2002; De Backer et al., 2003).

In the HBQ, the questions of use of medications, alcohol consumption, burnout, motivation, joint ache, illness or injury, insomnia, depression, and alcohol counselling by family members were originally posed as dichotomies (ie, yes or no). Also other variables, except alcohol consumption and physical exercise, were dichotomized as follows: marital status $(0=$ married and $1=$ single/ divorced/widowed), occupation $(0=$ office work and $1=$ industrial/construction work), and selfrated health $(1=$ good health (excellent/good) and $0=$ average/poor). Average health was combined with poor health on the basis of the extant

Primary Health Care Research \& Development 2008; 9: 96-104
(Manderbacka et al., 1998; Manor et al., 2000; Kivimäki et al., 2003).

With respect to the question of alcohol use, 'How often do you drink alcohol, 6 units at a time?', the response options were as follows: never, seldom, once a month, once a week, and daily. The variable was changed into three categories: $0=$ never/seldom, $1=$ once a month, and $2=$ once a week/daily. The question regarding physical exercise, 'How often do you have physical exercises lasting at least half an hour and getting winded and sweaty?', had three variables: $2=$ daily/4-6 times a week, $1=1-3$ times a week, and $0=2-3$ times a month or less.

Table 1 lists the dependent and independent variables of each model. The theoretical equivalent by Courtenay (2003) is presented in parentheses.

The general characteristics of the study sample are shown in Table 2, which outlines the distribution of outcome factors of the logistic models and the predictors of each model.

\section{Statistical analysis}

A stepwise logistic regression model was used to estimate the adjusted odds of each outcome by socio-demographic factors, health-behaviour factors, health-belief factors, and clinical factors. Six models were developed to test the effects of outcomes. Marital status and occupation were analysed by using force-entered procedures while 
Table 2 Characteristics of the study group from Health Behaviour Questionnaire

\begin{tabular}{|c|c|c|}
\hline Variable & Measurement & $n(\%)$ \\
\hline \multirow[t]{2}{*}{ Marital status } & Married (0) & $215(80.1)$ \\
\hline & Single, divorced, widowed (1) & $54(19.9)$ \\
\hline \multirow[t]{2}{*}{ Occupation } & Office worker (0) & $140(52.2)$ \\
\hline & Industrial worker (1) & $128(47.8)$ \\
\hline \multirow[t]{2}{*}{ Use of medications } & No $(0)$ & 77 (28.5) \\
\hline & Yes (1) & $193(71.5)$ \\
\hline Alcohol consumption & Never, seldom (0) & $132(49.1)$ \\
\hline \multirow[t]{2}{*}{6 units at a time } & Once a month (1) & $62(23.0)$ \\
\hline & Once a week or daily (2) & $75(27.9)$ \\
\hline \multirow[t]{3}{*}{ Physical exercise } & 4-7 times a week (2) & $45(16.7)$ \\
\hline & 1-3 times a week (1) & $142(52.7)$ \\
\hline & $2-3$ times a month or less $(0)$ & $82(30.6)$ \\
\hline \multirow[t]{2}{*}{ Self-rated health } & Average/poor $(0)$ & $150(55.4)$ \\
\hline & Good (1) & $121(44.6)$ \\
\hline \multirow[t]{2}{*}{ Motivation } & No $(0)$ & $83(31.0)$ \\
\hline & Yes (1) & $185(69.0)$ \\
\hline \multirow[t]{2}{*}{ Waist circumference } & $<94.0 \mathrm{~cm} \mathrm{(0)}$ & $121(44.3)$ \\
\hline & $\geqslant 94.0 \mathrm{~cm} \mathrm{(1)}$ & $152(55.7)$ \\
\hline \multirow[t]{2}{*}{ Body mass index } & $<25.0\left(\mathrm{~kg} / \mathrm{m}^{2}\right)(0)$ & $94(34.4)$ \\
\hline & $\geqslant 25.0\left(\mathrm{~kg} / \mathrm{m}^{2}\right)(1)$ & $179(65.6)$ \\
\hline \multirow[t]{2}{*}{ Burnout } & No $(0)$ & $183(67.5)$ \\
\hline & Yes (1) & $88(32.5)$ \\
\hline \multirow[t]{2}{*}{ Illness or injury } & No $(0)$ & $48(17.8)$ \\
\hline & Yes (1) & $221(82.2)$ \\
\hline \multirow[t]{2}{*}{ Insomnia } & No $(0)$ & $202(74.0)$ \\
\hline & Yes (1) & $71(26.0)$ \\
\hline \multirow[t]{2}{*}{ Depression } & No $(0)$ & $231(84.6)$ \\
\hline & Yes (1) & $42(15.4)$ \\
\hline \multirow[t]{2}{*}{ Joint ache } & No $(0)$ & $224(82.1)$ \\
\hline & Yes (1) & 49 (17.9) \\
\hline \multirow[t]{2}{*}{ Dental health } & Average/poor (0) & $124(45.4)$ \\
\hline & Good (1) & $148(54.4)$ \\
\hline \multirow{2}{*}{ Alcohol counselling by family members } & No (0) & $222(84.1)$ \\
\hline & Yes (1) & 42 (15.9) \\
\hline
\end{tabular}

the rest of the predictors were analysed by using each step conditional method.

The analysis was carried out using SPSS for Windows, version 11.0 (SPSS Inc., Chicago, IL, USA).

\section{Findings}

Models 1-5 present how the use of medications, alcohol consumption, self-rated health status, burnout, and motivation are associated with underlying health covariates (Table 3 ).

\section{Use of medications and alcohol consumption}

In Model 1, marital status $(P=0.050)$, occupation $(P=0.004)$, illness $(P \leqslant 0.001)$, and joint ache $(P=0.043)$ were significantly associated with medication use. Married men were slightly more likely to use medications than single or divorced men. Industrial workers were more likely to use medications than office workers $(\mathrm{OR}=2.75 ; 95 \% \mathrm{CI}, 1.38-5.46)$. Men who had an illness or injury were eight times more likely to use medications ( $\mathrm{OR}=8.02 ; 95 \% \mathrm{CI}, 3.71-17.30)$.

Alcohol counselling by family members was the most significant predictor of alcohol consumption in Model 2. Men who were counselled regarding alcohol use were 4.5-fold more likely not to use alcohol, 6 units at a time, than their peers $(\mathrm{OR}=4.47$; 95\% CI, 2.21-9.03). The other statistically significant predictor for alcohol consumption was BMI. Obese men $\left(B M I \geqslant 25.0 \mathrm{~kg} / \mathrm{m}^{2}\right)$ were two times more likely to use alcohol than men who had a normal BMI.

Primary Health Care Research \& Development 2008; 9: 96-104 
Table 3 Determinants of health behaviour: use of medications and alcohol consumption

\begin{tabular}{|c|c|c|c|c|}
\hline & \multicolumn{2}{|c|}{ Model 1 (Use of medications) } & \multicolumn{2}{|c|}{ Model 2 (Alcohol consumption) } \\
\hline & OR $(95 \% \mathrm{Cl})$ & $P$ value & OR $(95 \% \mathrm{Cl})$ & $P$ value \\
\hline Marital status & $0.49(0.24-0.99)$ & 0.050 & $1.73(0.87-3.44)$ & 0.121 \\
\hline Occupation & $2.75(1.38-5.46)$ & 0.004 & $1.33(0.75-2.38)$ & 0.333 \\
\hline Illness or injury & $8.02(3.71-17.30)$ & 0.001 & & \\
\hline Joint ache & $0.45(0.21-0.97)$ & 0.043 & & \\
\hline Body mass index $\left(\mathrm{kg} / \mathrm{m}^{2}\right)$ & & & $2.05(1.06-3.94)$ & 0.032 \\
\hline Alcohol counselling & & & $4.47(2.21-9.03)$ & 0.001 \\
\hline \multicolumn{5}{|c|}{ Determinants of health-related beliefs and expression of emotions: self-rated health and burnout } \\
\hline & \multicolumn{2}{|c|}{ Model 3 (Self-rated health) } & \multicolumn{2}{|l|}{ Model 4 (Burnout) } \\
\hline & OR $(95 \% \mathrm{Cl})$ & $P$ value & OR $(95 \% \mathrm{Cl})$ & $P$ value \\
\hline Marital status & $2.02(1.03-3.96)$ & 0.040 & $1.73(0.86-3.47)$ & 0.122 \\
\hline Occupation & $0.96(0.55-1.68)$ & 0.891 & $0.65(0.36-1.15)$ & 0.140 \\
\hline Waist (cm) & $2.58(1.48-4.47)$ & 0.001 & & \\
\hline Dental health & $0.36(0.21-0.62)$ & 0.001 & & \\
\hline Illness or injury & $0.28(0.13-0.59)$ & 0.001 & & \\
\hline Insomnia & & & $2.49(1.30-4.74)$ & 0.006 \\
\hline Depression & & & $4.87(2.18-10.87)$ & 0.001 \\
\hline \multicolumn{5}{|c|}{ Determinants of readiness to change unhealthy behaviours: motivation } \\
\hline & \multicolumn{2}{|c|}{ Model 5 (Motivation) } & & \\
\hline & OR $(95 \% \mathrm{Cl})$ & $P$ value & & \\
\hline \multicolumn{5}{|l|}{ Independent } \\
\hline Marital status & $0.48(0.24-0.95)$ & 0.034 & & \\
\hline Occupation & $0.49(0.28-0.86)$ & 0.014 & & \\
\hline \multicolumn{5}{|l|}{ Physical exercise } \\
\hline 2-3 times a month or less & 1.00 & & & \\
\hline $1-3$ times a week & $1.72(0.74-3.99)$ & 0.205 & & \\
\hline 4-7 times a week & $2.36(1.26-4.42)$ & 0.007 & & \\
\hline \multicolumn{5}{|l|}{ Alcohol consumption } \\
\hline Never, seldom & 1.00 & & & \\
\hline Once a month & $1.96(0.91-4.24)$ & 0.085 & & \\
\hline Once a week or daily & $2.45(1.28-4.69)$ & 0.007 & & \\
\hline
\end{tabular}

\section{Self-rated health and burnout}

In Model 3, marital status $(P=0.040)$, waist circumference $(P \leqslant 0.001)$, perceived dental health $(P \leqslant 0.001)$, and illness or injury $(P \leqslant 0.001)$ were significant predictors for self-rated health. Men who were married $(\mathrm{OR}=2.02 ; 95 \% \mathrm{CI}, 1.03-3.96)$, men who had a normal waist circumference, $(\mathrm{OR}=2.58 ; 95 \% \mathrm{CI}, 1.48-4.47)$, men who rated their dental health as good $(\mathrm{OR}=0.36 ; 95 \% \mathrm{CI}$, 0.21-0.62) or who did not suffer from illness or injury were more likely to regard their overall health as good $(\mathrm{OR}=0.28 ; 95 \% \mathrm{CI}, 0.13-0.59)$.
In Model 4, burnout was highly predicted by insomnia $(P=0.006)$ and depression $(P \leqslant 0.001)$. Men who suffered from insomnia $(\mathrm{OR}=2.49$; $95 \%$ CI, 1.30-4.74) or who were depressed $(\mathrm{OR}=4.87 ; 95 \% \mathrm{CI}, 2.18-10.87)$ had a strong association with a history of burnout.

In Model 5, motivation was significantly predicted by marital status $(P=0.034)$ and occupation $(P=0.014)$. Married men $(\mathrm{OR}=0.48$; 95\% CI, 0.24-0.95) and office workers (OR = $0.49 ; 95 \%$ CI, $0.28-0.86$ ) were more likely to be motivated than their peers. Additionally, physical 
exercise and alcohol consumption served statistically significant predictors for motivation. Men who exercised 4-7 times a week were over two times more likely to get motivated than inactive men $(\mathrm{OR}=2.36$; 95\% CI, 1.26-4.42). Similarly, no or infrequent use of alcohol was associated with readiness to change unhealthy behaviours $(\mathrm{OR}=0.28 ; 95 \% \mathrm{CI}, 0.13-0.59)$.

\section{Discussion}

\section{Main findings of this study}

Many relevant predictors that were significantly associated with the selected key determinants of health behaviour and health beliefs of middle-aged men were found in this study.

The use of medications analysis represents the response to stress. Existing illness or injury and occupation showed the strongest associations with medication use, in which industrial workers were more likely to use medication than office personnel.

Although, over two-thirds of men used medications for various symptoms, joint ache was only one indication. The two most common categories of occupational disease are musculoskeletal disorders and occupational stress (Coggon, 2005), which may increase the use of medications. Additionally, risk-taking behaviour, such as dangerous sports and other high-risk activities are more common among men than among women (Courtenay, 2003). Santana (2005) has highlighted that changes in occupation-related morbidity require new research approaches to provide protection for workers and improvements in health standards for workers in contemporary society.

Compared with single or divorced responders, married men were more likely to follow medical regimens, which may be a consequence of input by their spouses (Ramirez Garcia et al., 2006). On the basis of our results, it is not possible to know, however, what has been the utility of this usage for men's health.

Alcohol counselling by family members was strongly associated with less use of alcohol in our study. This finding supports a recent study, in which $22 \%$ of the Finnish men aged $35-44$ years reported to be counselled by family members, $3 \%$ by their physician, and $4 \%$ by public health nurses (Helakorpi et al., 2005). Thus, the role of family members as 'health keepers', is important not only for men but for entire families. According to Courtenay (2000), 'health matters are women's matters;' such collective beliefs and assumptions are referred to by social scientists and called social norms or subjective norms (Ajzen, 1985).

High levels of alcohol consumption have been associated with various physical diseases, accidentrelated injuries (Vollrath et al., 1993; Courtenay, 2003), mental health problems, difficulties at work, violence, and family problems (Courtenay, 2003). In Finland, heavy-drinking habits are on the rise (Lahelma et al., 2006); 20\% of the excess mortality is attributable to alcohol-related deaths, nearly $20 \%$ to other deaths from accidents and violence, and $13 \%$ to suicide (Martelin et al., 2006). Therefore, campaigns to educate spouses to have a more active role in alcohol counselling should lead to improved family health.

Lack of illness or injury, good dental health, and normal waist circumference had the strongest associations with perceived good health. These findings are consistent with previous results, according to which a variety of pathways link clinical measures to self-rated health (Manderbacka et al., 1998; Goldman et al., 2004; Myint et al., 2006) Special attention must be paid to a male's dental health. Recent findings indicate an association between dental disease and coronary heart diseases (Jansson et al., 2001).

From two adjusting factors, marital status was associated with self-rated health. Married men were more likely to perceive their health as good than single or divorced responders. This is in agreement with earlier results that compared with married men, unmarried men have more serious health risks and they engage in poorer health behaviour (Courtenay, 2000; Courtenay and Keeling, 2000; Sandman et al., 2000; NäslindhYlispangar et al., 2005; Lahelma et al., 2006).

Burnout was strongly predicted by insomnia and depression. This finding strengthened previous results that men rest less often and take care of themselves less well than women. This situation may decrease a male's well-being and cause burnout (Koskinen et al., 1999; Marks et al., 1999; Courtenay, 2003; Lahelma et al., 2006).

In 2005, 21\% of Finnish, working men reported sleeplessness during the last month, and $17 \%$ thought that they were more stressed than other

Primary Health Care Research \& Development 2008; 9: 96-104 
people. During the past year, $5 \%$ of adults experienced a severe episode of depression in Finland (Lönnqvist, 2006).

Active physical exercise and no or infrequent alcohol consumption were the most significant predictors for motivation to change unhealthy behaviours. In our study, over one-half of the men reported doing physical exercise at least once a week. It, however, was not enough to get them as motivated as men who did exercise at least four times a week $(\mathrm{OR}=1.7$ versus $\mathrm{OR}=2.4)$. This supports the finding that physical activity must be regular and repeated often to promote good health (Kukkonen-Harjula et al., 2005; Vuori, 2006).

A deeper understanding and further studies are needed to analyse the content and motivation of physical activities. Many questions remain unanswered in this study, such as: Are men taking risks while having sports during leisure time? or, Do they stress while having physical activity after work? or, Can they afford to have expensive sport hobbies?

The results concerning the association between excessive alcohol consumption and lack of motivation was in concordance with the findings of Courtenay (2003) that men respond to stress in lesshealthy way than do women, and they are more likely than women to use avoidant coping strategies, such as alcohol consumption and social isolation.

As with the use of medication, both adjusting demographic factors explained motivation. Married men and office workers were more likely to be ready to promote their health than their peers. This result again strengthens previous findings that social support (ie, family members) and higher work status have an influence on one's willingness to take care of their own health (Franklin et al., 2001).

The health psychological ideology that individuals are both responsible for and also experts regarding their own health is notable in discussing lifestyles and risk-taking behaviour (Marks et al., 1999; Courtenay, 2003). Attitudes and beliefs are important determinants of health, affecting both healthy and risky behaviours. Male gender is strongly associated with risk-taking behaviour; the more traditional health beliefs of masculinity they have, the more health risks they exhibit. These beliefs have been linked with smoking, excessive alcohol consumption, drug use, insomnia, depression, cardiovascular diseases, stress, and

Primary Health Care Research \& Development 2008; 9: 96-104 unhealthy dietary habits. (Fishbein and Ajzen, 1975; Ajzen, 1985; Courtenay, 2000; Courtenay and Keeling, 2000).

Gender-specific health is a deep and multidimensional issue to analyse, in which the determinants influence each other depending on social, mental, physiological, and environmental views. Actually, this issue is endless, and finally there are always interesting questions left waiting new answers and solutions.

\section{Limitations of this study}

At least some limitations to our study have to be considered. The first is the topic of interest. Research in matters as complicated as health behaviour and health-related beliefs are difficult and fragmentary, especially when there is a lack of a specific model or general theory. The second is the sampling. Our study population consisted only of men who were born in 1961 and lived in one area of a city. Third, the response rate was low because the participating men in this study were all volunteering, thus, results can be skewed. The fourth limitation is the measurement. Although the HBQ included several relevant questions that were considered equivalent to Courtney's determinants, many of them provided no new information owing to the low response rates.

Despite the limitations outlined above, these findings will help to improve our understanding of the influences of key determinants and their underlying factors on health and well-being among middle-aged men.

\section{What this study adds}

Many relevant predictors that were significantly associated with the selected key determinants of health behaviour and health beliefs of middleaged men were found in this study.

- Married men, office workers, men who were physically active, and men who used alcohol less frequently, were more likely to be motivated to change their health behaviours.

- Special attention must be paid to a male's dental health.

- Counselling by family members seems to be an important factor in the maintenance of less alcohol consumption. 
The promotion of regular physical activity and healthy lifestyles among middle-aged men is currently one of the most important priorities of preventive work in primary health care.

\section{Ethical approval}

The ethics committee for human research at Helsinki approved the study protocol. Informed consent was obtained from all participants and they were aware of the possibility to withdraw their participation at any time.

\section{Acknowledgements}

This study was supported by the Helsinki Heart District and the City of Helsinki. We wish to thank the public health nurses at these organisations for their contribution to this study.

\section{References}

Ajzen, I. 1985: From intentions and actions: a theory of planned behaviour. In Kuhl, J. and Beckmann A., editors, Action control: from cognition to behavior. Berlin: Springler-Verlag, 11-40.

Coggon, D. 2005: Occupational medicine at a turning point. Occupational \& Environmental Medicine 62, 281-83.

Courtenay, W. 2000: Constructions of masculinity and their influence on men's well-being: a theory of gender and health. Social Science and Medicine 50, 1385-401.

Courtenay, W. 2003: Key determinants of health and the wellbeing of men and boys. International Journal of Men's Health 2, 1-30.

Courtenay, W. and Keeling, R. 2000: Men, gender and health: toward an interdisciplinary approach. Journal of American College Health 48, 243-47.

De Backer, G., Ambrosioni, E., Borch-Jonhsen, K., Brotons, C., Cifkova, R., Dallongeville, J., Ebrahim, S., Faergeman, O., Graham, I., Mancia, G., Manger Cats, V., Orth-Gomer, K., Perk, J., Pyörälä, K., Rodicio, J.L., Sans, S., Sansoy, V., Sechtem, U., Silber, S., Thomsen, T. and Wood, D. 2003: European guidelines on cardiovascular disease prevention in clinical practice. Third Task Force of European and other Societies on Cardiovascular Disease Prevention in Clinical Practice. European Heart Journal 34, 1601-610.

Fishbein, M. and Ajzen, I. 1975: Belief, attitude, intention and behaviour: an introduction to theory and research. Reading, MA: Addison-Wesley, 12-14, 405-406.

Franklin, S., Larson, M., Khan, S., Wong, N., Leip, E., Kannel, W. and Levy, D. 2001: Does the relation of blood pressure to coronary heart disease risk change with aging? The Framingham heart study. American Heart Association 103, 1245-249.

Galdas, P., Cheater, F. and Marshall, P. 2005: Men and healthseeking behavior: literature review. Journal of Advanced Nursing 49, 616-23.

Goldman, N., Glei, D.A. and Chang, M.C. 2004: The role of clinical risk factors in understanding self-rated health. Annals of Epidemiology 14, 49-57.

Griffiths, S. 1996: Men's health: unhealthy lifestyles and unwillingness to seek medical help. BMJ 312, 69-70.

Helakorpi, S., Uutela, A., Prättälä, R. and Puska, P. 2000: Health behaviour and health among Finnish adult population. Helsinki: Hakapaino Oy. Publications of National Health Institute, 1-12.

Helakorpi, S., Uutela, A., Prättälä, R. and Puska, P. 2005: Health behaviour and health among Finnish adult population. Helsinki: Hakapaino Oy. Publications of National Health Institute, 143, 155, 158.

Jansson, L., Laustedt, S., Frithiof, L. and Theobald, H. 2001: Relationship between oral health and mortality in cardiovascular diseases. Journal of Clinical Periodontology 28, 762-68.

Kivimäki, M., Head, J., Ferrie, J.E., Shipley, M.J., Vahtera, J. and Marmot, M. 2003: Sickness absence as a global measure of health: evidence from mortality in the Whitehall II prospective cohort. BMJ 16, 327-64.

Koskinen, S., Martelin, T. and Rissanen, H. 1999: Differences and trends in mortality by marital status. Journal of Social Medicine 3, 271-84.

Kukkonen-Harjula, K.T., Borg, P.T., Nenonen, A.M. and Fogelholm, M.G. 2005: Effects of a weight maintenance program with or without exercise on the metabolic syndrome: a randomized trial in obese men. Preventive Medicine 41, 784-90.

Lahelma, E., Karisto, A., Mannila, S. and Notkola, V. 2006: Social structure and culture. In Koskinen, S., Aromaa, A., Huttunen, J. and Teperi, J., editors, Health in Finland. Helsinki, Finland: National Public Health Institute KTL, National Research and Development Centre for Welfare and Health, Ministry of Social Affairs and Health, 22-24.

Lakka, H-M., Laaksonen, D., Lakka, T., Niskanen, L., Kumpusalo, E., Tuomilehto, J. and Salonen, J. 2002: The metabolic syndrome and total and cardiovascular disease mortality in middle-aged men. JAMA 288, 2709-716.

Lash, S.J., Eisler, R.M. and Schulman, R.S. 1990: Cardiovascular reactive to stress in men: effects of masculine gender role stress appraisal and masculine performance challenge. Behavior Modification 14, 3-20.

Lönnqvist, J. 2006: Suicides in Health in Finland. In Koskinen, S., Aromaa, A., Huttunen, J. and Teperi J., editors, Health in Finland. Helsinki, Finland: National Public Health Institute KTL, National Research and Development Centre for Welfare and Health. Ministry of Social Affairs and Health, 70-71.

Primary Health Care Research \& Development 2008; 9: 96-104 
Manderbacka, K., Lahelma, E. and Martikainen, P. 1998: Examining the continuity of self-rated health. International Journal of Epidemiology 27, 208-13.

Manor, O., Sharon, M. and Chris, P. 2000: Dichotomous or categorical response? Analysing self-rated health and lifetime social class. International Journal of Epidemiology 29, 149-57.

Marks, D., Murray, M., Evans, B. and Willing, C. 1999: Health psychology. Theory, research and practice. London: Sage Publications, 12-14.

Martelin, T., Koskinen, S. and Valkonen, T. 2006: Mortality. In Koskinen, S., Aromaa, A., Huttunen, J. and Teperi, J., editors, Health in Finland. Helsinki, Finland: National Public Health Institute KTL, National Research and Development Centre for Welfare and Health. Ministry of Social Affairs and Health, 48-50.

Moynihan, C. 1998: Theories of masculinity. BMJ 317, 1072-075.

Myint, P.K., Welch, A.A., Luben, R.N., Wainwright, N.M.J., Surtees, P.G., Bingham, S.A., Wareham, N.J., Smith, R.D., Harvey, J.M. and Khaw, K.-T. 2006: Obesity indices and self-reported functional health in men and women in the EPIC-Norfolk. Obesity 14, 884-93.

Näslindh-Ylispangar, A., Sihvonen, M., Vanhanen, H. and Kekki, P. 2005: Self-rated health and risk factors for metabolic syndrome among middle-aged men. Public Health Nursing 22, 515-22.

Ramirez Garcia, J.I., Chang, C.L., Young, J.S., Lopez, S.R. and Jenkins, J.H. 2006: Family support predicts psychiatric medication usage among Mexican American individuals with schizophrenia. Social Psychiatry \& Psychiatric Epidemiology 41, 624-31.

Roter, D.L. and Hall, J.A. 1997: Doctors talking with patients/ patient talking with doctors: improving communication in medical visits. Westport, CT: Auburn House.

Sandman, D., Simantow, E. and An, C. 2000: Out of touch: American men and the health care system. New York: Commonwealth Fund.

Santana, V.S. 2005: Beyond the duality of disease and illness in occupational medicine. Occupational \& Environmental Medicine 62, 284-85.

Van der Pligt, P. 1994: Risk appraisal and health behaviour. In Rutter, D. and Quine, L., editors, Social psychology and health: European perspectives. Avebury: Aldeshot, 131-35.

Verbrugge, L. 1985: Gender and health: an update on hypotheses and evidence. Journal of Health and Social Behaviour 26, 1156-182.

Vollrath, M., Knoch, D. and Cassano, L. 1993: Personality, risky health behaviour, and perceived susceptibility to health risks. European Journal of Personality 13, $39-50$.

Vuori, I. 2006: Physical exercise. In Koskinen, S., Aromaa, A., Huttunen, J. and Teperi, J., editors, Health in Finland. Helsinki, Finland: National Public Health Institute KTL, National Research and Development Centre for Welfare and Health. Ministry of Social Affairs and Health, 32.

Weinstein, N. 1987: Unrealistic optimism about susceptibility to health problems: conclusions from a community-wide sample. Journal of Behavioral Medicine 10, 481-500. 